\title{
GMR
}

\section{Molecular identification and phylogenetic analysis of important medicinal plant species in genus Paeonia based on rDNA-ITS, matK, and $r b c L$ DNA barcode sequences}

\author{
W.J. Kim, Y. Ji, G. Choi, Y.M. Kang, S. Yang and B.C. Moon \\ K-herb Research Center, Korea Institute of Oriental Medicine, Yuseong-daero, \\ Yuseong-gu, Daejeon, Republic of Korea \\ Corresponding author: BC Moon \\ E-mail: bcmoon@kiom.re.kr
}

Genet. Mol. Res. 15 (3): gmr.15038472

Received January 20, 2016

Accepted March 11, 2016

Published August 5, 2016

DOI http://dx.doi.org/10.4238/gmr.15038472

Copyright $(92016$ The Authors. This is an open-access article distributed under the terms of the Creative Commons Attribution ShareAlike (CC BY-SA) 4.0 License.

ABSTRACT. This study was performed to identify and analyze the
phylogenetic relationship among four herbaceous species of the genus
Paeonia, P. lactiflora, P. japonica, $P$. veitchii, and $P$. suffruticosa,
using DNA barcodes. These four species, which are commonly
used in traditional medicine as Paeoniae Radix and Moutan Radicis
Cortex, are pharmaceutically defined in different ways in the national
pharmacopoeias in Korea, Japan, and China. To authenticate the
different species used in these medicines, we evaluated rDNA-internal
transcribed spacers (ITS), matK and $r b c \mathrm{~L}$ regions, which provide
information capable of effectively distinguishing each species from one
another. Seventeen samples were collected from different geographic
regions in Korea and China, and DNA barcode regions were amplified
using universal primers. Comparative analyses of these DNA barcode 
sequences revealed species-specific nucleotide sequences capable of discriminating the four Paeonia species. Among the entire sequences of three barcodes, marker nucleotides were identified at three positions in $P$. lactiflora, eleven in $P$. japonica, five in $P$. veitchii, and 25 in $P$. suffruticosa. Phylogenetic analyses also revealed four distinct clusters showing homogeneous clades with high resolution at the species level. The results demonstrate that the analysis of these three DNA barcode sequences is a reliable method for identifying the four Paeonia species and can be used to authenticate Paeoniae Radix and Moutan Radicis Cortex at the species level. Furthermore, based on the assessment of amplicon sizes, inter/intra-specific distances, marker nucleotides, and phylogenetic analysis, rDNA-ITS was the most suitable DNA barcode for identification of these species.

Key words: DNA barcode; Paeonia species; rDNA-ITS; matK; rbcL; Species discrimination

\section{INTRODUCTION}

In Korean herbal medicine, approximately 540 species of medicinal plants have been traditionally applied to the treatment of many diseases and symptoms. The Paeonia genus includes two important traditional herbal medicines, Paeoniae Radix and Moutan Radicis Cortex. Moutan Radicis Cortex is exclusively made from P. suffruticosa; however, Paeoniae Radix is described differently in the Korean, Chinese, and Japanese pharmacopoeia (Korea Institute of Oriental Medicine, 2015). In addition, in the Pharmacopoeia of the People's Republic of China, P. lactiflora is used in two distinct herbal medicines, Paeniae Radix Rubra and Paeoniae Radix Alba (Korea Institute of Oriental Medicine, 2015). Paeoniae Radix Alba and P. japonica are both referred to as "Baekjak" and consequently, P. japonica and P. lactiflora may be confused due to the similar pronunciations of these homonyms.

In prescriptions for traditional medicine, Paeoniae Radix and Moutan Radicis Cortex are used to treat different symptoms. Paeoniae Radix is commonly used to treat blood extravasation, relieve pain, clear fever, and protect the liver (Li et al., 2016). In contrast, Moutan Radicis Cortex is used to activate the blood and treat blood extravasation in the heart, liver, and kidney (Kim et al., 2007; Korea Institute of Oriental Medicine, 2015). Therefore, in order to prevent inaccurate or inauthentic prescriptions that include these herbal medicines, it is very important to distinguish among the four Paeonia species.

Plant species and herbal medicines are identified using a variety of methods, including analyses of morphologic characteristics, chemical compositions, and molecular genetic variations (Jiang et al., 2014; Moon et al., 2015; Zhao et al., 2015). For successful morphological identification, a pharmacognostic expert must have extensive professional experience that is acquired from evaluating large numbers of medicinal herbs. In addition, an objectively assessable classification key must be constructed based on internal or external morphological traits, such as the starch grain of parenchyma cells, shape of phloem or xylem, crystal of the cortex, and epidermis or cross-section of the dried medicinal herb (Mahadani and Ghosh, 2013; Chen et al., 2014). Chemical analysis requires costly techniques, including high-performance liquid chromatography, UV/Vis spectrophotometry, and near-infrared

Genetics and Molecular Research 15 (3): gmr.15038472 
spectroscopy (Jiang et al., 2014; Wang et al., 2015). Moreover, the results of chemical analysis can vary depending on environmental factors and physiological conditions, and the necessary supplies can be extremely expensive (Joshi et al., 2004; Jiang et al., 2014).

Molecular markers represent a potentially cheaper and more accurate alternative to chemical analyses. Because DNA markers are based on unique nucleotide sequences and are not affected by environmental factors or physiological conditions, their analysis can provide rapid and accurate monitoring of multiple types of samples including fresh plants, dried medicinal herbs, and processed foods (Joshi et al., 2004; Ma et al., 2014; Vassou et al., 2015). Among the diverse molecular genetic tools available for identifying medicinal plant species, analysis of DNA barcodes based on short DNA sequences in the nuclear or organellar genomes is commonly used for efficient and accurate species identification (Jiang et al., 2014; Zhao et al., 2015). The chloroplast and nuclear genomes contain multiple candidate DNA barcode regions with high substitution rates. Among these regions, rDNA-internal transcribed spacers (ITS), $r b c \mathrm{~L}, m a t \mathrm{~K}, p s b \mathrm{~A}-t r n \mathrm{H}, \operatorname{trn} \mathrm{L}-\mathrm{F}$, and $t r n \mathrm{H}$ have been used to identify plant species and analyze phylogenetic relationships (Tripathi et al., 2013; Chen et al., 2014; Aziz et al., 2015; Vassou et al., 2015). The $r b c$ L region is considered to be a universal DNA barcode region, but it is less useful for species identification due to its slow rate of molecular evolution (Tripathi et al., 2013; Ma et al., 2014). Another universal DNA barcode region, matK, exhibits higher rates of sequence variation and is therefore, superior for purposes of species discrimination. The Plant Working Group of the Consortium for the Barcode of Life (CBOL) recommends using a combination of $r b c \mathrm{~L}$ and $m a t \mathrm{~K}$ regions as a universal DNA barcode for Plantae (CBOL Plant Working Group, 2009). Alternatively, the rDNA-ITS is suitable as a barcode region because it can very reliably identify species in diverse plant genera (Tripathi et al., 2013; Vassou et al., 2015; Zhao et al., 2015). Consequently, rDNA-ITS sequences have the potential to distinguish between medicinal plants and their close relatives. Recently, these DNA barcode regions have frequently been applied to diverse herbal medicines to authenticate medicinal plant species and analyze the molecular phylogeny of medicinal herbs (Kim et al., 2013; Ma et al., 2014; Aziz et al., 2015; Zheng et al., 2015). In this study, we comparatively analyzed the three DNA barcode regions, rDNA-ITS, matK, and $r b c \mathrm{~L}$, to evaluate their ability to identify the four, potentially confused medicinal Paeonia species. We identified species-specific single nucleotide polymorphisms (SNPs, i.e., marker nucleotides) that are sufficient to discriminate among these species, and confirmed that these DNA barcodes are suitable for the taxonomic identification and classification of Paeonia samples at the species level.

\section{MATERIAL AND METHODS}

\section{Plant material}

Seventeen samples of $P$. lactiflora, P. japonica, P. veitchii, or P. suffruticosa were used as plant material in this study (Table 1). Samples collected from different geographical regions of the Republic of Korea and China were quick-frozen in liquid nitrogen and then stored at $-80^{\circ} \mathrm{C}$ in a deep freezer. Independent individuals of each species were identified by the Classification and Identification Committee of the Korea Institute of Oriental Medicine (KIOM), which is comprised of experts in the fields of plant taxonomy, botany, pharmacognosy, and herbology. These plant materials were provided accession numbers and specimens were preserved in the Herbarium of the KIOM.

Genetics and Molecular Research 15 (3): gmr.15038472 
W.J. Kim et al.

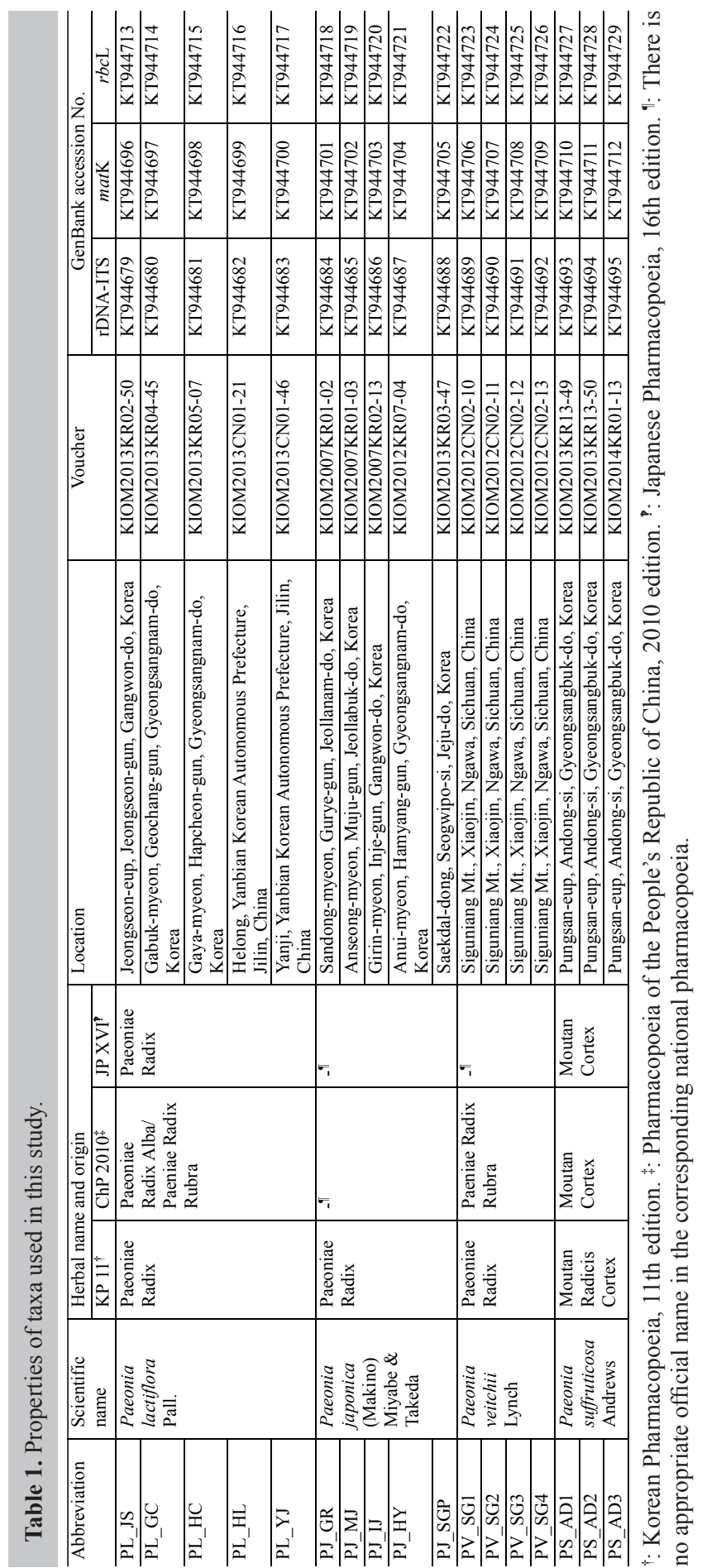

Genetics and Molecular Research 15 (3): gmr.15038472 


\section{Genomic DNA extraction}

Genomic DNA was extracted from approximately $100 \mathrm{mg}$ fresh leaves using a Precellys ${ }^{\mathrm{TM}}$ Grinder (Bertin Technologies, Montigny-le-Bretonneux, France) and the DNeasy ${ }^{\circledR}$ Plant Mini Kit (Qiagen, Valencia, CA, USA). Quality and quantity of genomic DNA were monitored using UV/Vis spectrophotometry (ND-1000, NanoDrop, Wilmington, DE, USA) and resolution was determined using $1.5 \%$ agarose gel electrophoresis with a 100-bp DNA ladder (Solgent, Daejeon, Korea). Each genomic DNA sample was diluted to approximately $15 \mathrm{ng} / \mu \mathrm{L}$ in TE ( $\mathrm{pH} \mathrm{8.0)}$ ) for use as a PCR template.

\section{PCR amplification of DNA barcoding regions and sequencing}

The DNA barcoding regions, rDNA-ITS, matK, and $r b c \mathrm{~L}$ were amplified using universal primers for vascular plants: ITS1 (5'- TCC GTA GGT GAA CCT GCG G-3') and ITS4 (5'- TCC TCC GCT TAT TGA TAT GC-3') for the entire ITS region; matK AF (5'- CTA TAT CCA CTT ATC TTT CAG GAG T-3') and matK 8R (5'- AAA GTT CTA GCA CAA GAA AGT CGA-3') for a $\sim 1.3-\mathrm{kb}$ fragment of the matK gene; and $r b c \mathrm{~L} \mathrm{~F}$ (5'-ATG TCA CCA CAA ACA GAA ACT AAA GC-3') and $r b c$ L R (5'-TCC TTT TAG TAA AAG ATT GGG CGG AG-3') for a $\sim 1.6-\mathrm{kb}$ fragment of the $r b c \mathrm{~L}$ gene (White et al., 1990; Olmstead and Reeves, 1995; Kato et al., 1998). PCR mixtures (40 $\mu \mathrm{L}$ total volume) consisted of approximately 15 ng genomic DNA, 20 pM each forward and reverse primers, SolgTM $2 X$ Taq PCR SmartMix I (Solgent), and distilled, deionized water. The PCR conditions were as follows: initial denaturation for $2 \mathrm{~min}$ at $95^{\circ} \mathrm{C} ; 35$ cycles of 1 min denaturation at $95^{\circ} \mathrm{C}, 40 \mathrm{~s}$ annealing at $53^{\circ} \mathrm{C}$, and $1 \mathrm{~min}$ extension at $72^{\circ} \mathrm{C}$; and final extension for $5 \mathrm{~min}$ at $72^{\circ} \mathrm{C}$. The amplified PCR products were resolved by electrophoresis on $1.5 \%$ agarose gels with a 100 -bp DNA ladder (Solgent). Specific amplified bands, approximately $750 \mathrm{bp}$ for rDNA-ITS, $1.3 \mathrm{~kb}$ for matK, and $1.5 \mathrm{~kb}$ for $r b c \mathrm{~L}$ were purified from the gels using the Gel Extraction Kit (Qiagen) and sub-cloned into pGEM ${ }^{\circledR}$-T Easy Vector (Promega, Madison, WI, USA). The ligation reaction was prepared as follows: $4.5 \mu \mathrm{L}$ DNA; $0.5 \mu \mathrm{L} \mathrm{pGEM}^{\circledR}-\mathrm{T}$ Easy Vector; and $5 \mu \mathrm{L}$ Ligation Mix (DNA Ligation Kit $<$ Mighty Mix $>$, TaKaRa Bio Inc., Otsu, Shiga, Japan). The ligation mixture was incubated at room temperature for $30 \mathrm{~min}$, and then $5 \mu \mathrm{L}$ ligation mixture was used to transform competent cells (Escherichia coli strain JM109). Recombinant white colonies were picked and sequenced. Both strands of the insert DNA were sequenced by dideoxynucleotide chain termination on an automatic DNA sequence analyzer (ABI3730, Applied Biosystems Inc., Foster City, CA, USA). Each DNA barcode region was sequenced a minimum of three times per sample. The resultant nucleotide sequences of the rDNA-ITS, matK, and $r b c \mathrm{~L}$ genes for all 17 samples were registered in NCBI GenBank (Table 1).

\section{Sequence analysis and genetic relationship analysis}

Approximately 800-bp sequences obtained from bi-directional sequencing with T7 and SP6 promotor were assembled and edited using the BioEdit version 7.2.5 (Hall, 1999) software. The contigs were aligned to analyze the intra- and inter-species variations in the sequence. For the analysis of sequence identity and evolution, inter- or intra-species genetic distances were calculated using the Kimura-2-parameter (K2P) model in the MEGA6 (Molecular Evolutionary Genetics Analysis Version 6.0) program (Tamura et al., 2013, http://

Genetics and Molecular Research 15 (3): gmr.15038472 
www.megasoftware.net). The phylogenetic analysis based on the rDNA-ITS, matK, and $r b c \mathrm{~L}$ sequences was performed using MEGA version 6.06 (Kimura, 1980; Tamura et al., 2013) software. The phylogenetic tree was constructed using the neighbor-joining (NJ) method with the K2P model, pairwise deletion for gaps/missing data treatment, and 1000 replications for bootstrap. Hamamelis japonica was chosen as an out-group control. The resulting NCBI GenBank accession numbers are GU576652 for rDNA-ITS, AF198091 for matK, and AY263940 for $r b c \mathrm{~L}$.

\section{RESULTS}

\section{PCR amplification and genetic diversity of DNA barcoding region}

PCR was performed on all 17 Paeonia samples. Amplification of the three DNA barcode regions, rDNA-ITS, matK, and $r b c \mathrm{~L}$, with universal primers yielded $100 \%$ PCR efficiency. Thus, the universal primers, ITS1/ITS4, matK AF/matK 8R, and $r b c \mathrm{~L} \mathrm{~F} / r b c \mathrm{~L} \mathrm{R}$, are suitable for use in the genus Paeonia. Amplicons were sequenced after sub-cloning and the final lengths of the sequences were $724 \mathrm{bp}$ for rDNA-ITS; 1511-1530 bp for $r b c \mathrm{~L}$; and $1238 \mathrm{bp}$ for matK (Table 2). Genetic divergence within or between the species was calculated using the DNA barcode sequences ( $\underline{\text { Tables S1, } \mathbf{S 2}}$ and $\underline{\mathbf{S 3}}$ ). The intra-specific distances ranged from $0.18 \%$ to $0.95 \%$ in rDNA-ITS, 0.00 to $0.05 \%$ in $m a t \mathrm{~K}$, and 0.00 to $0.07 \%$ in $r b c \mathrm{~L}$. In rDNA-ITS, $P$. veitchii exhibited the highest variation rate among the four species $(0.95 \%)$, whereas $m a t \mathrm{~K}$ and $r b c \mathrm{~L}$ differed very little relative to the other three species $(0.00$ and $0.03 \%$, respectively). Similar to the intra-specific distance for the three DNA barcodes in P. veitchii, the variability of the rDNA-ITS sequence was also greater than those for $m a t \mathrm{~K}$ and $r b c \mathrm{~L}$ in the other three Paeonia species. The average inter-specific distance of the rDNA-ITS region was highest in $P$. suffruticosa, followed by $P$. veitchii, $P$. japonica, and $P$. lactiflora; the variability of matK was highest in P. suffruticosa, followed by P. japonica, P. veitchii, and P. lactiflora; and the variability of $r b c \mathrm{~L}$ was highest in $P$. suffruticosa, followed by $P$. veitchii, P. lactiflora, and $P$. japonica. The inter-species distances ranged from 2.35 to $2.73 \%$ in rDNA-ITS, 0.49 to $1.22 \%$ in $m a t \mathrm{~K}$, and 0.30 to $0.40 \%$ in $r b c \mathrm{~L}$. P. suffruticosa had the highest inter-specific distance in all three DNA barcode regions, and P. lactiflora had the lowest distance in both rDNA-ITS and matK. These results suggest that the traditional DNA barcodes, rDNA-ITS, $m a t \mathrm{~K}$, and $r b c \mathrm{~L}$, could discriminate the original plant species between Paeoniae Radix and Moutan Radicis Cortex and rDNA-ITS sequence is the most suitable DNA marker for distinguishing between four Paeonia species.

\section{Sequence analysis and species discrimination}

Species-specific substitutions and indels, i.e., marker nucleotides that are sufficient to authenticate the individual species, were identified from a comparative analysis of the entire nucleotide sequences of the four Paeonia species (Tables 2-5). From the comparative alignments of rDNA-ITS, we obtained species-specific substitutions at one position for $P$. lactiflora, four for P. japonica, two for P. veitchii, and nine for P. suffruticosa (Table 3). We defined these species-specific substitutions as marker nucleotides because they were crucial for identifying each species. For example, when all of the 17 rDNA-ITS sequences of four Paeonia species were aligned against the P. lactiflora PL_JS sample reference sequence,

Genetics and Molecular Research 15 (3): gmr.15038472 
cytosine (C) 83 was substituted for guanine (G) only in P. suffruticosa (Table 3). This unique species-specific substitution is enough to discriminate $P$. suffruticosa from the three other Paeonia species. In matK, species-species marker nucleotides were identified at five positions in P. japonica, one in P. veitchii, and 12 in P. suffruticosa, but not in P. lactiflora (Table 4).

Table 2. Statistics for three DNA barcodes used in this study.

\begin{tabular}{|c|c|c|c|c|c|}
\hline DNA barcode region & Scientific name & Amplicon length (bp) & Intra-specific distance & Inter-specific distance & Marker nucleotide site \\
\hline \multirow[t]{4}{*}{ rDNA-ITS } & P. lactiflora & 742 & $0.0057 \pm 0.0033$ & $0.0235 \pm 0.0055$ & 1 \\
\hline & P. japonica & 742 & $0.0024 \pm 0.0017$ & $0.0243 \pm 0.0034$ & 4 \\
\hline & P. veitchii & 742 & $0.0095 \pm 0.0038$ & $0.0249 \pm 0.0069$ & 2 \\
\hline & P. suffruticosa & 742 & $0.0018 \pm 0.0008$ & $0.0273 \pm 0.0060$ & 9 \\
\hline \multirow[t]{4}{*}{$m a t \mathrm{~K}$} & P. lactiflora & 1238 & $0.0005 \pm 0.0004$ & $0.0049 \pm 0.0037$ & 0 \\
\hline & P. japonica & 1238 & $0.0003 \pm 0.0004$ & $0.0072 \pm 0.0043$ & 5 \\
\hline & P. veitchii & 1238 & $0.0000 \pm 0.0000$ & $0.0049 \pm 0.0039$ & 1 \\
\hline & P. suffruticosa & 1238 & $0.0005 \pm 0.0005$ & $0.0122 \pm 0.0019$ & 12 \\
\hline \multirow[t]{4}{*}{$r b c \mathrm{~L}$} & P. lactiflora & 1530 & $0.0003 \pm 0.0003$ & $0.0031 \pm 0.0007$ & 2 \\
\hline & P. japonica & 1511 & $0.0007 \pm 0.0005$ & $0.0030 \pm 0.0063$ & 2 \\
\hline & P. veitchii & 1511 & $0.0003 \pm 0.0004$ & $0.0031 \pm 0.0007$ & 2 \\
\hline & P. suffruticosa & 1511 & $0.0000 \pm 0.0000$ & $0.0040 \pm 0.0003$ & 4 \\
\hline
\end{tabular}

Table 3. rDNA-ITS sequence variation among the four Paeonia species.

\begin{tabular}{|c|c|c|c|c|c|c|c|c|c|c|c|c|c|c|c|}
\hline & \multicolumn{15}{|c|}{ Aligned position } \\
\hline & 79 & 83 & 99 & 104 & 113 & 118 & 123 & 161 & 168 & 169 & 544 & 559 & 651 & 658 & 678 \\
\hline P. lactiflora & $\mathrm{A}$ & $\mathrm{C}$ & $\underline{T}$ & $\mathrm{~T}$ & $\mathrm{~T}$ & $\mathrm{G}$ & $\mathrm{G}$ & A & $\mathrm{A}$ & $\mathrm{G}$ & $\mathrm{A}$ & $\mathrm{C}$ & $\mathrm{G}$ & A & $\mathrm{A}$ \\
\hline P. japonica & $\underline{\mathbf{G}}$ & . & $\mathrm{C}$ & . & . & . & . & $\underline{\mathrm{C}}$ & $\underline{T}$ & $\underline{C}$ & . & $\cdot$ & . & . & . \\
\hline P. veitchii & . & $\cdot$ & $\mathrm{C}$ & $\underline{\mathrm{C}}$ & $\cdot$ & $\cdot$ & $\cdot$ & $\cdot$ & $\cdot$ & $\cdot$ & $\cdot$ & $\underline{\mathbf{T}}$ & . & $\cdot$ & $\cdot$ \\
\hline P. suffruticosa & $\underline{C}$ & $\underline{\mathbf{G}}$ & $\mathrm{C}$ & . & $\underline{\mathrm{C}}$ & $\underline{\mathbf{A}}$ & $\underline{\mathbf{A}}$ & . & $\cdot$ & $\cdot$ & $\underline{\mathbf{G}}$ & . & $\underline{\mathbf{A}}$ & $\underline{\mathbf{G}}$ & $\underline{T}$ \\
\hline
\end{tabular}

Dots $(\cdot)$ indicate nucleotides identical to those of P. lactiflora. Underlined bold characters represent species-specific substitutions.

Table 4. matK sequence variation among the four Paeonia species.

\begin{tabular}{|c|c|c|c|c|c|c|c|c|c|c|c|c|c|c|c|c|c|c|}
\hline & \multicolumn{18}{|c|}{ Aligned position } \\
\hline & 48 & 134 & 138 & 139 & 348 & 385 & 533 & 537 & 540 & 588 & 625 & 772 & 823 & 903 & 935 & 983 & 1027 & 1040 \\
\hline P. lactiflora & $\mathrm{G}$ & $\mathrm{T}$ & A & $\mathrm{C}$ & $\mathrm{T}$ & $\mathrm{G}$ & A & A & $\mathrm{C}$ & $\mathrm{C}$ & $\mathrm{C}$ & $\mathrm{C}$ & $\mathrm{G}$ & $\mathrm{C}$ & $\mathrm{G}$ & $\mathrm{C}$ & $\mathrm{T}$ & $\mathrm{C}$ \\
\hline P. japonica & $\underline{\mathbf{A}}$ & $\cdot$ &. & $\underline{T}$ & $\cdot$ & $\cdot$ & . & $\underline{\mathbf{G}}$ & $\cdot$ & $\underline{T}$ & $\underline{T}$ & $\cdot$ & $\cdot$ & . & $\cdot$ &. & $\cdot$ & $\cdot$ \\
\hline P. veitchii & $\cdot$ & $\cdot$ & . & $\cdot$ & $\underline{G}$ & $\cdot$ & . &. & $\cdot$ &. & . & $\cdot$ & $\cdot$ & $\cdot$ & . & $\cdot$ & $\cdot$ & $\cdot$ \\
\hline P. suffruticosa & $\cdot$ & $\mathbf{G}$ & $\underline{\mathbf{G}}$ & . & & $\mathbf{T}$ & $\underline{C}$ & . & $\mathbf{A}$ & . & . & $\mathbf{T}$ & $\mathbf{A}$ & $\mathbf{T}$ & $\underline{\mathbf{T}}$ & $\mathbf{T}$ & C & $\mathbf{T}$ \\
\hline
\end{tabular}

Dots $(\cdot)$ indicate nucleotides identical to those of $P$. lactiflora. Underlined bold characters represent species-specific substitutions.

Table 5. $r b c \mathrm{~L}$ sequence variation among the four Paeonia species.

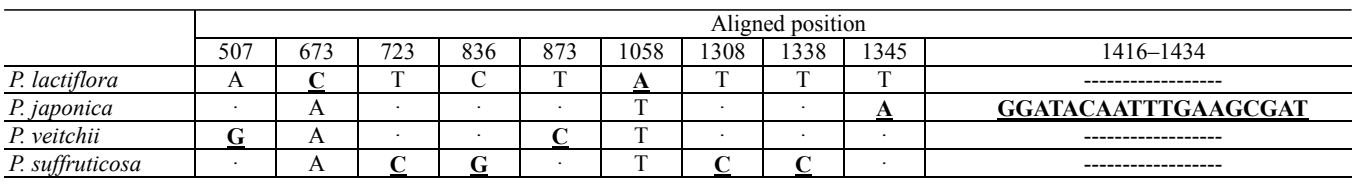

Dots $(\cdot)$ indicate nucleotides identical to those of $P$. lactiflora, and dashes $(-)$ represent nucleotide deletions at the aligned nucleotide positions. Underlined bold characters and dashes (-) represent species-specific substitutions and indels, respectively.

Genetics and Molecular Research 15 (3): gmr.15038472 
From the analysis of $r b c \mathrm{~L}$ sequences, we also obtained species-specific marker nucleotides at two positions in P. lactiflora, one position in P. japonica, two positions in P. veitchii, and four positions in $P$. suffruticosa (Table 5). In addition to these species-specific substitutions, a 19-bp P. japonica-specific indel region that was applicable to the marker nucleotides, was the only such sequence in the three barcode regions, and was observed in $r b c \mathrm{~L}$ (Table 5). Although P. lactiflora-specific marker nucleotides were not identified in $m a t \mathrm{~K}$, the combination of $m a t \mathrm{~K}+r b c \mathrm{~L}$, which is a universal plant DNA barcode recommended by CBOL, provided enough information to authenticate each of the four Paeonia species. The results obtained using the sequence differences in the three DNA barcodes revealed that $P$. suffruticosa, which had the highest inter-specific distance, i.e., the highest genetic variation relative to the other three Paeonia species (Table 2), had the highest number of marker nucleotides. Thus, inter-specific distance positively correlates with the presence of marker nucleotides.

\section{Phylogenetic analyses}

To evaluate the phylogenetic relationships among the four herbaceous Paeonia species, phylogenetic trees were constructed by applying the NJ method to the entire sequences of rDNA-ITS, matK, and $r b c \mathrm{~L}$. All 17 individual samples were clustered into four groups constituting homogeneous clades within each species that reflected the intra-specific variation in all DNA barcodes (Figures 1-3). As shown in the results of the phylogenetic tree, when all three DNA barcode sequences were employed, P. lactiflora was closer genetically to $P$. veitchii than to the other two Paeonia species, while P. suffruticos $a$ was more distant to the other three Paeonia species. Bootstrap values clustered at the species level ranged from 81 to $99 \%$ in rDNA-ITS, 60 to $99 \%$ in $m a t \mathrm{~K}$, and 53 to $98 \%$ in $r b c \mathrm{~L}$ (Figures 1-3). Three of the Paeonia species had bootstrap values greater than $60 \%$; the exception was the $P$. suffruticosa $r b c \mathrm{~L}$ gene, which clustered at 53\%. In particular, the rDNA-ITS allowed a clearer classification of the four species than either matK or $r b c \mathrm{~L}$. To distinguish species based on the phylogenetic tree, the minimum bootstrap values were $81 \%$ in rDNA-ITS, $60 \%$ in $m a t \mathrm{~K}$, and $53 \%$ in $r b c \mathrm{~L}$. Therefore, the rDNA-ITS barcode sequence provided higher resolution for the identification of clusters that constitute homogeneous clades within each Paeonia species. From these phylogenetic analyses, we confirm that the identification of the four Paeonia species can be achieved using sequence variability in their rDNA-ITS, matK, and $r b c \mathrm{~L}$ sequences.

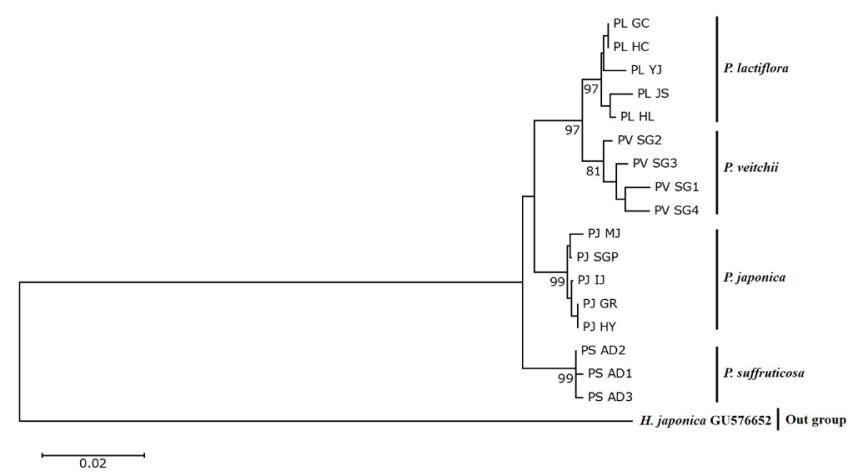

Figure 1. Phylogenetic tree with 1000 bootstrap replicates based on rDNA-ITS sequences from four Paeonia species and Hamamelis japonica. NJ bootstrap values greater than $60 \%$ are shown above the branches.

Genetics and Molecular Research 15 (3): gmr.15038472 


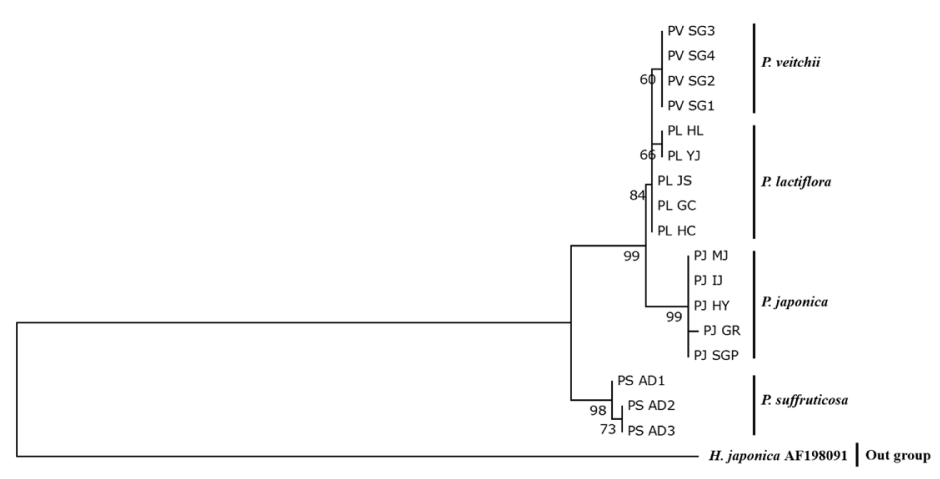

Figure 2. Phylogenetic tree with 1000 bootstrap replicates based on matK sequences from four Paeonia species and Hamamelis japonica. NJ bootstrap values greater than $60 \%$ are shown above the branches.

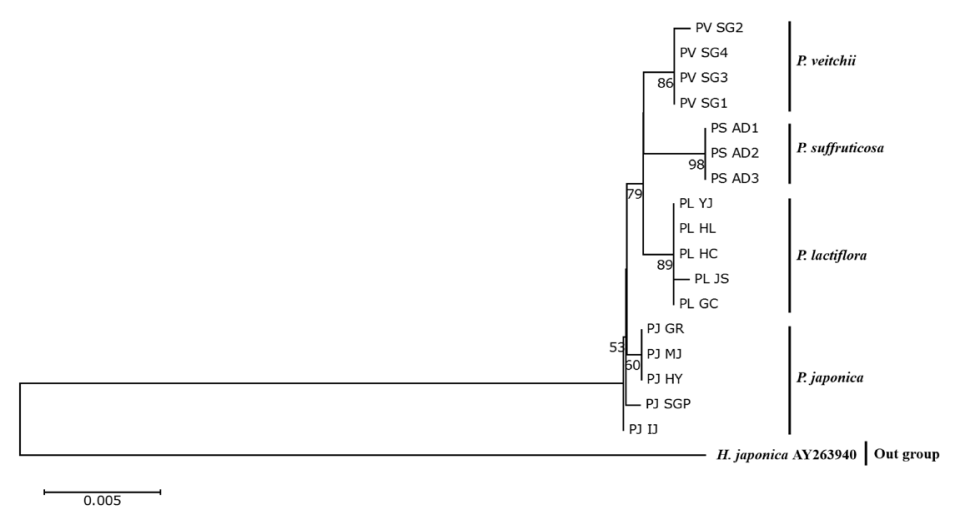

Figure 3. Phylogenetic tree with 1000 bootstrap replicates based on $r b c \mathrm{~L}$ sequences from four Paeonia species and Hamamelis japonica. NJ bootstrap values greater than $50 \%$ are shown above the branches.

\section{DISCUSSION}

Diverse technical methods, including analyses of morphology, chemical composition, and molecular markers, have been used to identify medicinal plant species (Semagn et al., 2006; Jiang et al., 2014; Zhao et al., 2015). Due to limitations in the discriminatory power of morphological and chemical analysis, DNA barcoding has been suggested as a SNP marker for efficient and accurate species identification using short regions of nuclear or organellar DNA (Joshi et al., 2004; CBOL Plant Working Group, 2009; Jiang et al., 2014; Ma et al., 2014; Vassou et al., 2015). The ideal DNA barcode regions for this purpose should be applicable to diverse plant species. Therefore, the main focus of DNA barcoding is the discovery of universal sequence regions that contain conserved sequences, as well as diversity across species. Universal primers are designed to be complementary to the conserved sequences and flanking sites of the variable barcoding regions (Olmstead and Reeves, 1995; Kato et al., 1998; White et al., 1990; CBOL Plant Working Group, 2009). Furthermore, barcode sequences 
should vary among species but not within species (Ma et al., 2014). In this study, we assessed rDNA-ITS, $m a t \mathrm{~K}$, and $r b c \mathrm{~L}$ as candidate DNA barcode regions for the identification of four Paeonia species.

The results of PCR amplification revealed that the three DNA barcode regions all had $100 \%$ amplification and sequencing efficiency, and are suitable for amplification in all four Paeonia species using universal primers. The inter- and intra-specific distances of rDNAITS were greater than those of $m a t \mathrm{~K}$ and $r b c \mathrm{~L}$ (Table 2). Previous study has also shown that the inter-specific sequence divergence among DNA barcode regions is highest in ITS2, followed by matK and $r b c \mathrm{~L}$, in Sida cordifolia and Tulipa edulis (Ma et al., 2014; Vassou et al., 2015). DNA barcode regions in plant systems are divided into protein-coding and noncoding regions. Non-coding regions, such as the nuclear ribosomal internal transcribed spacer (rDNA-ITS) and the $p s b \mathrm{~A}-t r n \mathrm{H}$ and $t r n \mathrm{~L}-\mathrm{F}$ intergenic spacers, evolve quickly by acquisition of substitutions and indels, whereas protein-coding regions such as $m a t \mathrm{~K}$ and $r b c \mathrm{~L}$ do not (Tripathi et al., 2013; Vassou et al., 2015). Our measured values of inter- and intra-specific distances are consistent with those reported previously and they confirm that the rDNA-ITS locus has evolved more rapidly than matK and $r b c \mathrm{~L}$ in the four Paeonia species (Tripathi et al., 2013; Aziz et al., 2015; Vassou et al., 2015; Zhao et al., 2015).

Based on substitutions and indels, we obtained marker nucleotides that can be used for discrimination at the species level. Such marker nucleotides were present in rDNA-ITS and $r b c \mathrm{~L}$, but not in $m a t \mathrm{~K}$. Although $m a t \mathrm{~K}$ is one of the most rapidly evolving protein-coding regions in plastids (Tripathi et al., 2013; Ma et al., 2014; Vassou et al., 2015), matK of $P$. lactiflora contains no marker nucleotides and consequently cannot be used to distinguish $P$. lactiflora from the other three Paeonia species. Although matK has no discriminatory power, it could still be utilized as a DNA barcode region. Consequently, CBOL recommends the combination of $m a t \mathrm{~K}+r b c \mathrm{~L}$ as a universal DNA barcode for plants, with rDNA-ITS and $p s b \mathrm{~A}$ $\operatorname{tr} n \mathrm{H}$ used as supplementary barcodes (CBOL Plant Working Group, 2009). Consistent with the $\mathrm{CBOL}$ recommendation, multiple studies reported that inter-specific discrimination requires a combination of two or more DNA barcode regions, e.g., ITS2+ $p s b \mathrm{~A}-t r n \mathrm{H}$ or $r b c \mathrm{~L}+\mathrm{ITS}+p s b \mathrm{~A}-$ $\operatorname{trn} \mathrm{H}$ (Tripathi et al., 2013; Vassou et al., 2015). Therefore, although individual DNA barcode regions have sufficient discriminatory power, we nevertheless strongly recommend that combinations of DNA barcode regions, such as ITS $+r b c \mathrm{~L}$, ITS $+m a t \mathrm{~K}$, or ITS $+m a t \mathrm{~K}+r b c \mathrm{~L}$, can be used to achieve more accurate identification.

In phylogenetic analyses, the 17 samples formed a monophyletic group within each species, with bootstrap values greater than $50 \%$. In particular, using the rDNA-ITS barcode, samples could be classified into the four species. mat $\mathrm{K}$ and $r b c \mathrm{~L}$ also facilitated efficient separation of the four Paeonia species. In sequence analysis of matK, which has no $P$. lactiflora-specific sequence, the phylogenetic tree exhibited better species identification resolution than the marker nucleotide analysis. In contrast, the phylogenetic tree of $r b c \mathrm{~L}$ yielded poorer species resolution than did the marker nucleotide analysis in P. japonica. As an alternative method, we suggest using the $m a t \mathrm{~K}+r b c \mathrm{~L}$ combination as recommended by the CBOL plant working group.

Although DNA barcoding provides a useful method for discriminating the species, this technique takes 2-4 days and requires the following processes: PCR, cloning, sequence analysis, and alignment with GenBank. Therefore, further studies are needed to develop more rapid and efficient techniques for this species, such as melting curve analysis and multiplexsequence characterized amplified region markers.

Genetics and Molecular Research 15 (3): gmr.15038472 
In conclusion, based on the assessment of all results including inter/intra-specific distance, marker nucleotides, phylogenetic trees, and amplicon sizes, the most suitable DNA barcode for identification of Paeonia species was rDNA-ITS. We also suggest that the $m a t \mathrm{~K}+r b c \mathrm{~L}$ combination also can be used to efficiently discriminate between the four Paeonia species. On the basis of these findings, we propose that the three DNA barcode regions, rDNA-ITS, matK, and $r b c \mathrm{~L}$, can be used to discriminate between the four Paeonia species. Furthermore, species-specific marker nucleotides identified in this study will help to accurately authenticate each species and standardize the quality of the two traditional herbal medicines, Paeoniae Radix and Moutan Radicis Cortex.

\section{Conflicts of interest}

The authors declare no conflict of interest.

\section{ACKNOWLEDGMENTS}

We thank the 'Classification and Identification Committee of the KIOM' for critical authentication of plant materials and the Herbarium of Korea Standard Herbal Resources (herbarium code KIOM) for the provision of plant materials. Research supported by the grant 'Development of Basic Technologies for the Domestic Cultivation of Herbal Medicine Resources' (\#K14417 and \#K15421) from the Ministry of Science, ICT, and Future Planning (MSIP) of Korea to the KIOM.

\section{REFERENCES}

Aziz NAA, Ahmad MI and Naim DM (2015). Molecular DNA identification of medicinal plants used by traditional healers in Malaysia. Genet. Mol. Res. 14: 15937-15947.http://dx.doi.org/10.4238/2015.December.7.5

CBOL Plant Working Group (2009). A DNA barcode for land plants. Proc. Natl. Acad. Sci. USA 106: 12794-12797. http:// dx.doi.org/10.1073/pnas.0905845106

Chen S, Pang X, Song J, Shi L, et al. (2014). A renaissance in herbal medicine identification: from morphology to DNA. Biotechnol. Adv. 32: 1237-1244. http://dx.doi.org/10.1016/j.biotechadv.2014.07.004

Hall TA (1999). BioEdit: a user-friendly biological sequence alignment editor and analysis program for Windows 95/98/ NT. Nucleic Acids Symp. Ser. 41: 95-98.

Jiang C, Cao L, Yuan Y, Chen M, et al. (2014). Barcoding melting curve analysis for rapid, sensitive, and discriminating authentication of saffron (Crocus sativus L.) from its adulterants. BioMed Res. Int. 2014: 809037. http://dx.doi. org/10.1155/2014/809037

Joshi K, Chavan P, Warude D and Patwardhan B (2004). Molecular markers in herbal drug technology. Curr. Sci. 87: 159-165.

Kato H, Oginuma K, Gu Z, Hammel B, et al. (1998). Phylogenetic relationships of Betulaceae based on matK sequences with particular reference on the positions of Ostryopsis. Acta Phytotax. Geobot 49: 89-97.

Kim J, Lee H, Lee Y, Oh BG, et al. (2007). Inhibition effects of Moutan Cortex Radicis on secretion of eotaxin in A549 human epithelial cells and eosinophil migration. J. Ethnopharmacol. 114: 186-193. http://dx.doi.org/10.1016/j. jep.2007.07.038

Kim MK, Wang H, Kim YJ, Sathiyamoorthy S, et al. (2013). Molecular authentication by multiplex-PCR of three similar medicinal plant species: Cynanchum wilfordii, Cynanchum auriculatum and Polygonum multiflorum (Fallopia multiflorum). J. Med. Plants Res. 7: 2584-2589.

Kimura M (1980). A simple method for estimating evolutionary rates of base substitutions through comparative studies of nucleotide sequences. J. Mol. Evol. 16: 111-120. http://dx.doi.org/10.1007/BF01731581

Korea Institute of Oriental Medicine. (2015). Defining Dictionary for Medicinal Herbs ‘Hanyak Giwon Sajeon'. Available at [http://boncho.kiom.re.kr/codex/]. Accessed November 20, 2015.

Genetics and Molecular Research 15 (3): gmr.15038472 
Li X, Wang Y, Sun Q, Xu B, et al. (2016). Molecularly imprinted solid phase extraction in a syringe filter for determination of triazine herbicides in Radix Paeoniae Alba by ultra-fast liquid chromatography. Talanta 148: 539-547. http:// dx.doi.org/10.1016/j.talanta.2015.11.027

Ma H, Zhu Z, Zhang X, Miao Y, et al. (2014). Species identification of the medicinal plant Tulipa edulis (Liliaceae) by DNA barcode marker. Biochem. Syst. Ecol. 55: 362-368. http://dx.doi.org/10.1016/j.bse.2014.03.038

Mahadani P and Ghosh SK (2013). DNA barcoding: A tool for species identification from herbal juices. DNA Barcodes (Berlin) 1: 35-38.

Moon BC, Ji Y, Lee YM, Kang YM, et al. (2015). Authentication of Akebia quinata DECNE. from its common adulterant medicinal plant species based on the RAPD-derived SCAR markers and multiplex-PCR. Genes Genomics 37: 23-32. http://dx.doi.org/10.1007/s13258-014-0225-6

Olmstead RG and Reeves PA (1995). Evidence for the polyphyly of the Scrophulariaceae based on choloroplast $r b c \mathrm{~L}$ and $n d h \mathrm{~F}$ sequences. Ann. Mo. Bot. Gard. 82: 176-193. http://dx.doi.org/10.2307/2399876

Semagn K, Bjørnstad $\AA$ and Ndjiondjop MN (2006). An overview of molecular marker methods for plants. Afr. J. Biotechnol. 5: 2540-2568.

Tamura K, Stecher G, Peterson D, Filipski A, et al. (2013). MEGA6: Molecular evolutionary genetics analysis version 6.0. Mol. Biol. Evol. 30: 2725-2729. http://dx.doi.org/10.1093/molbev/mst197.

Tripathi AM, Tyagi A, Kumar A, Singh A, et al. (2013). The internal transcribed spacer (ITS) region and trnH-psbA [corrected] are suitable candidate loci for DNA barcoding of tropical tree species of India. PLoS One 8: e57934. http://dx.doi.org/10.1371/journal.pone.0057934

Vassou SL, Kusuma G and Parani M (2015). DNA barcoding for species identification from dried and powdered plant parts: a case study with authentication of the raw drug market samples of Sida cordifolia. Gene 559: 86-93. http:// dx.doi.org/10.1016/j.gene.2015.01.025

Wang Y, Wang P, Xu C, Sun S, et al. (2015). Discrimination and chemical characterization of different Paeonia lactifloras (Radix Paeoniae Alba and Radix Paeoniae Rubra) by infrared macro-fingerprint analysis-through-separation. J. Mol. Struct. 1099: 68-76. http://dx.doi.org/10.1016/j.molstruc.2015.06.035

White TJ, Bruns T, Lee S and Taylor J (1990). Amplification and direct sequencing of fungal ribosomal RNA genes for phylogenetics. In: PCR Protocols: A guide to methods and applications. (Innis MA, Gelfand DH, Sninsky JJ, White TJ, eds.). Academic Press, New YorK, pp. 315-322.

Zhao Y, Li Y, Liu Y and Yang YF (2015). DNA barcoding for efficient identification of Ixiolirion species (Ixioliriaceae). Genet. Mol. Res. 14: 1903-1910.http://dx.doi.org/10.4238/2015.March.13.19

Zheng WH, Zhuo Y, Liang L, Ding WY, et al. (2015). Conservation and population genetic diversity of Curcuma wenyujin (Zingiberaceae), a multifunctional medicinal herb. Genet. Mol. Res. 14: 10422-10432.http://dx.doi. org/10.4238/2015.September.8.3

\section{Supplementary material}

Table S1. Genetic distances determined using rDNA-ITS sequences from 17 samples of four Paeonia species.

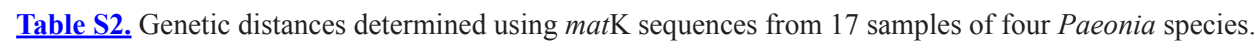

Table S3. Genetic distances determined using $r b c \mathrm{~L}$ sequences from 17 samples of four Paeonia species. 